\title{
AS PALAVRAS E AS COISAS: UMA HISTÓRIA DO PENSAMENTO QUE NOS AJUDA A ENTENDER A EMERGÊNCIA DA QUESTÃO DO SUJEITO NA FILOSOFIA MODERNA
}

THE ORDER OF THINGS: A THOUGHT HISTORY THAT HELPS US TO UNDERSTAND THE EMERGENCE OF SUBJECT MATTER IN MODERN PHILOSOPHY

Luama Socio*

\section{RESUMO}

Através de uma análise histórica do desenvolvimento do pensamento ocidental no contexto das línguas francesa e inglesa, tendo como ponto de partida uma reflexão aprofundada sobre o século XVIII, a obra de Foucault, As palavras e as coisas, nos faz entender que a raiz do pensamento moderno repousa na linguagem como extensão dos próprios modos de funcionamento da mente humana e de seus sujeitos. A linguagem não é apenas representação, no sentido de espelho ou expressão do mundo percebido. Foucault irá performatizar essa questão com seu próprio discurso, realizando nitidamente um método que podemos classificar de "kantiano", em que o procedimento geral da comparação, como movimento básico do funcionamento das categorias mentais, aparece como expediente organizacional, tanto do discurso de Foucault, quanto como sub-tema do material analisado. Essa história do pensamento nos ajuda a entender a questão da emergência do sujeito na filosofia moderna.

PALAVRAS-CHAVE: História. Pensamento. Sujeito. Discurso. Linguagem.

\section{ABSTRACT}

Through a historical analysis of the development of Western thought in the context of English and French languages, and yet takes a deep reflection of the eighteenth century, the book Foucault, "The words and things", makes us understand that the beginnings of modern thought rests in language as an extension of the operating modes of human minds and their subjects. The language is not only representation, meaning mirror, image or expression of the perceived world. Foucault will make a performance this issue through his own speech, he will perform a method we classify of "Kantian". The widespread employment of comparison, as

\footnotetext{
*Doutora em Filosofia pela USP. E-mail: 1uamasocio@yahoo.com.br.
} 
basic movement the functioning of the mental categories, appears as way to organize so the Foucault speech, so the sub theme in this history of thought. And this history of thought helps us understand the problem of the emergence the subject in the modern philosophy. KEYWORDS: history. Thought. Subject. Speech. Language

O título da obra de Foucault, As palavras e as coisas, remete com exatidão aos dois campos conceituais sobre os quais se dará a análise e a interpretação crítica da relação entre eles. Foucault aborda essa antiga e perene questão filosófica concentrando-se no ponto de articulação dessa espécie de "dobra histórica" entre um passado e um futuro, que é a época clássica do milênio anterior, representada pelo século XVIII. Faz isso apoiando-se nesse ponto como num eixo para a roda do seu discurso sobre a relação entre palavras e coisas. Os raios dessa roda estão representados pelas questões de cada um dos dez capítulos da obra que, por sua vez, estão subdivididos em tópicos específicos.

Foucault caracteriza essa dobra histórica de várias formas, através de diversas palavras, ao longo de todo o texto, por meio de um levantamento exaustivo de seus aspectos refletidos no corpus filosófico arregimentado na empreitada discursiva. A época clássica nomeia o recorte histórico em que ainda não se terá consolidado o projeto científico nos seus modos mais abstratos, especializados, mas que já abandonara os antigos modos filosóficos na acepção tradicional de sabedoria universal. Trata-se, segundo Foucault, de uma época de levantamento de dados, dedicada a classificações e ordenações estruturais: "Nem vida, nem ciência da vida na época clássica; nem tão-pouco filologia. Mas uma história natural, uma gramática geral” (1967, p. 220).

A forma de caracterizar esse eixo do discurso então se destaca: emerge o método comparativo, que vai apontar a aproximação de elementos ora considerados semelhantes, ora considerados diferentes entre si, sempre tendo como padrão de "medida" a época clássica. Assim, por exemplo, referindo-se ao elemento riqueza, no tópico Análise das riquezas, primeiro tema do capítulo seis, intitulado “Trocar", Foucault mostra como filósofos do século XVIII ordenam as distinções herdadas das franjas do passado, ao mesmo tempo que propõem uma nova concepção a partir do movimento da própria organização das reflexões antes disponíveis:

Sapere aude - Belo Horizonte, v. 7 - n. 12, p. 58-69, Jan./Jun. 2016 - ISSN: 2177-6342 
[...] E assim, peça por peça, pedaço a pedaço, a economia política teria silenciosamente ordenado os seus temas essenciais até o momento em que, retomando num outro sentido, a análise da produção, Adam Smith teria trazido à luz o processus da divisão crescente do trabalho, Ricardo o papel desempenhado pelo capital e J. B. Say algumas das leis fundamentais da economia de mercado. Desde então a economia política teria começado a existir com o seu objeto próprio e a sua coerência interior. (FOUCAULT, 1967, p. 222).

O primeiro capítulo de As palavras e as coisas nos afigura como o degrau inicial da espiral discursiva - que se delineará ao longo de mais nove capítulos -, descrevendo uma possibilidade da problematização do sujeito como significado na palavra que, aqui, aparece oportunamente sobreposta `a problemática da representação, ponto inicial da questão da relação da linguagem com as coisas, simbolizada pelo quadro de Velásquez.

O texto prosseguirá nessa espiral em seus desdobramentos, começando por tocar aquele hipotético estado inicial da história do pensamento, localizado na anterioridade do século clássico, no ponto de indistinção entre palavras e coisas no sentido em que, tanto umas como outras, são entendidas como concretudes, e não como abstrações, já que o pensamento analógico, próprio da época anterior ao classicismo, concebe o "mesmo" se desdobrando em formas sempre semelhantes a si próprio. O senso de concretude estaria associado a esse senso de semelhança caracterizado por uma visão de mundo que pressupõe coisas como marcas de coisas. "A marca e aquilo que ela designa são, exatamente, da mesma natureza" (FOUCAULT, 1967, p. 50). Na opinião de Foucault, o predomínio dessa metodologia da similitude incorre numa repetição empobrecedora do conhecimento, no sentido de ser aditiva, e não criativa. Aqui vemos o contraste dessa visão de mundo, que incorre na consequência da finitude, com a visão de mundo que permite a leitura feita do quadro de Velásquez no primeiro capítulo, que incorre, ao contrário, na consequência da infinitude. Se no século XVI, conhecer era interpretar, no século de Foucault, conhecer será, talvez, criar.

Depois vem a análise dos aspectos que sinalizam a modificação do pensamento caracterizado anteriormente. O símbolo da passagem de uma visão de mundo para outra é a grande obra de Cervantes: "D. Quixote lê o mundo para demonstrar os livros. E as provas que ele obtém não são mais do que o reflexo das semelhanças. [...] A escrita e as coisas já não se assemelham” (FOUCAULT, 1967, p. 71-2). Assim o século XVII já anuncia uma nova maneira de pensar. Para ilustrar essa questão, Foucault cita a influência de Francis Bacon, com sua visão de um futuro científico já desligando-se das formas da similitude, e Descartes, 
inaugurador da era do sujeito e, portanto, da era do método e da análise na história da filosofia, nas modificações do pensar ocidental. Passa-se de uma mentalidade da similitude para a mentalidade da diferença: “A atividade do espírito [...] já não consistirá portanto em aproximar as coisas [...] mas em discernir [...]. Nesse sentido, o discernimento impõe à comparação a procura primitiva e fundamental da diferença" (FOUCAULT, 1967, p. 82). O signo se desvincula da similitude e passa a ser sinal para a análise, e não para a verdade. Os sinais naturais cedem a importância para os sinais artificiais, para as linguagens, para os sistemas, que se tornarão predominantes daqui por diante.

Assinala-se com isso o desaparecimento da estrutura ternária do símbolo, ou seja, o apagamento da "coisa representada", que é doravante substituída por uma organização estritamente binária, em que o significante já representa o representado, sem a ideia de permeio. Há uma espécie de contração na estrutura da representação. Porém dissociando-se o signo da similitude, dissocia-se palavra e conhecimento e, como num efeito dominó, o conhecimento consequentemente tornar-se-á dependente do empirismo. Nesse ponto instalase uma contradição: "no entanto, para o conhecimento, a similitude é uma moldura indispensável. Porque uma realidade ou relação de ordem não pode ser restabelecida entre duas coisas a não ser que a sua semelhança permita compará-las" (FOUCAULT, 1967, p. 98).

O abrandamento dessa contradição surgirá com ideia de "gênese", a qual seria a combinação do trabalho da imaginação (que ajustará a natureza humana com a natureza fora do homem), juntamente com o reconhecimento dos "murmúrios" de similitude, oriundos do antigo modo de pensar, dando lugar a uma mentalidade filosófica e científica da "ordem", representada pela álgebra, como método de ordenação das naturezas simples, e pela taxonomia, como método da ordenação das naturezas complexas. Entre esses dois sistemas, dá-se uma dinâmica que preenche conclusões que vão da ideia de universal para a ideia de particular (álgebra) e vice-versa (taxonomia).

A taxonomia, evocando a imaginacão do continuum entre as partes nomeadas, faz emergir a gênese como explicação; e da combinação de mathesis (o elemento da álgebra) com gênese, nascem os quadros simbólicos dos saberes que, pode-se dizer, formam redes de significação totalmente novas e autônomas com relação a alguma possível referencialidade originária dos sistemas anteriores. "É nessa região que se encontra a história natural [...] a teoria da moeda e do valor [...] a gramática geral” (FOUCAULT, 1967, p. 105-106). E para Foucault, se "semelhante disposição" do pensamento clássico aparentemente terá fim com a 
Artigo: As palavras e as coisas: uma história do pensamento que nos ajuda a entender a emergência da questão do sujeito na filosofia moderna

influência de Kant - da qual surgirá o pensamento relacionado `as disciplinas da interpretação, exemplificadas por Nietzsche e Freud no século XIX, adentrando-se pelo século $\mathrm{XX}$ até o próprio Foucault -, ao mesmo tempo persistirá sob os quadros das "disciplinas formais". Sob os quadros dessas disciplinas a condição da palavra é a da própria representação identificada como condição do pensamento: "a linguagem representa o pensamento, como o pensamento se representa a si mesmo" (FOUCAULT, 1967, p. 110). Parece haver aí aquele típico esforço científico em direção a uma concepção de clareza no estabelecimento dos significados, com base no acervo de referencialidades dos quadros das disciplinas.

E é justamente desse contexto - em que o significado se dá através dessa espécie de transparência do pensamento inscrito diretamente no significante, em que a linguagem "desaparece" como linguagem - que emergirá a crítica, a qual vincula-se ao conceito de "discurso" como essa coisa que utiliza a palavra como representação do pensamento "ele próprio”. E essa crítica é possível porque foi possível, na época clássica, o pensamento sobre as funções por trás da palavra. Ou seja, a crítica se faz espelho desse espelho que é a gramática, a disciplina científica da linguagem surgida como a gramática geral do século XVIII. Os conceitos "funcionamento" e "discurso" estão aqui inter-relacionados: "Uma vez elidida a existência da linguagem, subsiste na representação apenas o seu funcionamento: a sua natureza e as suas virtudes de discurso” (FOUCAULT, 1967, p. 114).

\section{II}

O discurso na sua fase pré-crítica, só é também discurso porque sub-repticiamente se apoia nas sínteses das expressões linguísticas, as quais Foucault denomina ideologias, as quais representarão o sujeito que na crítica (surgida a partir de Kant) emergirá desvinculado, transcendental: "esta origem manifestada num discurso contínuo é a Ideologia, uma linguagem que redobra, em toda a sua extensão, o fio espontâneo do conhecimento" (FOUCAULT, 1967, p. 119). E se aqui a Ideologia dá a impressão de se localizar num nível interno e infinito em suas possibilidades nos quadros disciplinares, na verdade a linguagem, como elemento básico desses quadros, surge como complemento limitador para essa infinidade vislumbrada da Ideologia: “Todavia, a linguagem não é conhecimento senão sob uma forma irreflexa: impõe-se do exterior aos indivíduos que ela guia, quer eles queiram quer 
não" (FOUCAULT, 1967, p. 122). E nesse sentido podemos concluir que é a linguagem que pensa no indivíduo, e não o contrário. "Saber é falar bem [...]; As ciências são línguas 'perfeitas', na medida mesmo em que as línguas são ciências não desbravadas" (FOUCAULT, 1967, p. 122). As histórias do conhecimento, as enciclopédias, as quantidades de conhecimento aparecem aí.

Junto com elas aparece já o germe da centralidade do ser, identificada como que cientificamente, dentro das estruturas gramaticais referidas na gramática geral. Foucault sugere que um gramático do final do século XVIII hipoteticamente definiria "os nomes como formas, os adjetivos como cores e o verbo como a tela sobre a qual eles surgem" (1967, p. 135). Todavia, ‘a medida que a gramática também se torna uma espécie de ciência autônoma composta pelo quadrilátero das teorias da proposição, articulação, designação e derivação, dando-se como objeto do conhecimento, aquela centralidade entrevista do ser passa para o segundo plano dessa história do pensamento. A gramática como objeto é sintetizada, simbolizada, pelo conceito do nome. "Denominar é ao mesmo tempo dar a representação verbal de uma representação e colocá-la num quadro geral. Toda a teoria clássica da linguagem se organiza em torno desse ser privilegiado" (FOUCAULT, 1967, p. 164). Essa é a fonte da ideia de exatidão como qualidade potencialmente linguística: "só o juízo pode ser verdadeiro ou falso. Mas se todos os nomes fossem exatos [...] não haveria nenhuma dificuldade em pronunciar juízos verdadeiros” (p. 164).

Observamos que Foucault expressa todo o seu discurso num estilo que o configura como uma materialidade espacializada, concretizada em movimento dinâmico entre seus elementos principais. Esse estilo fica bem evidenciado no tema do "nome", o qual é explicado como sendo ao mesmo tempo, o ponto "para o qual convergem todas as estruturas da língua [...], e o ponto a partir do qual toda a teoria da linguagem pode entrar numa relação com a verdade donde será julgada" (FOUCAULT, 1967, p. 164).

Assim a era clássica ainda não é a era da abstração radical como forma discursiva ou como forma de pensamento. Por ser o século da nomeação, ainda existiam, por exemplo, os seres vivos, e não a vida, para a história natural. "A história natural não é mais do que a nomeação do visível” (FOUCAULT, 1967, p. 178). É nesse século que ganha sentido a ideia de "estrutura", a qual Foucault define como "essa designação do visível que, por uma espécie de escolha pré-linguística, permite a este transcrever-se na linguagem” (p. 186). Aparecem as ideias de descrição, enumeração de características, métodos, sistemas. De forma que "a teoria 
Artigo: As palavras e as coisas: uma história do pensamento que nos ajuda a entender a emergência da questão do sujeito na filosofia moderna

da história natural não é indissociável da da linguagem” (p. 122). Porém, a natureza dessa associação não está na transposição de método, conceito, modelo ou racionalidade de uma para outra, "mas de uma disposição fundamental do saber que ordena o conhecimento dos seres pela possibilidade de os representar num sistema de nomes” (p. 213).

Não obstante o caráter "arqueológico" e, portanto, bastante ilustrativo, no que concerne à pormenorização do arcabouço histórico como demonstrativo de uma alternativa de caracterização do desenvolvimento do pensamento no contexto das línguas francesa e inglesa, a obra de Foucault nos faz entender que a raiz do pensamento moderno repousa na linguagem como extensão dos próprios modos de funcionamento da mente humana e de seus sujeitos, e não apenas como espelho ou expressão do mundo percebido. Foucault irá perfazer, com seu próprio discurso, uma exposição em que utilizará nitidamente um método que podemos classificar de "kantiano"1, em que o procedimento geral da comparação, como movimento básico do funcionamento das categorias mentais, aparece como expediente organizacional, tanto do discurso de Foucault, quanto como subtema do material analisado.

Entendemos, portanto, As palavras e as coisas, como uma obra do Foucault "historiador do pensamento", na acepção utilizada por Kleber Prado Filho (2013, p. 88):

\begin{abstract}
A história do pensamento se sustenta metodologicamente numa arqueologia das problematizações e aponta para uma história crítica do presente. Mais que propriamente discursos, interessa a Foucault a emergência histórica de temas e problemas em nossa cultura, bem como a operação dos nossos modos históricos de pensar, nossos regimes de produção de verdades, as possibilidades e impossibilidades que nos são dadas para o exercício político do pensamento. Portanto, afirmar M. Foucault como historiador do pensamento implica imediatamente desligá-lo da tradição da história do conhecimento e das ciências, bem como recusar sua inscrição como 'teórico do discurso', título que sugere uma leitura estruturalista de Foucault, ou uma leitura do 'Foucault estruturalista', que é possível, mas considero inadequada.
\end{abstract}

Complementando esse ângulo de visão, citamos aqui algumas palavras dos editores da edição francesa da "Gênese e estrutura da Antropologia de Kant", que é a tese complementar de Foucault para As palavras e as coisas, corroborando a pertinência interpretativa do conteúdo dessa obra como história do pensamento, bem como seu alinhamento com o legado kantiano:

\footnotetext{
1 Kant mostrará, principalmente na Crítica da razão pura, que conhecimentos a priori podem ser justificados não só em termos de combinações mentais - a partir das operações específicas entre os conceitos originados dos objetos -, mas como forma de conhecimento inerente `a própria estrutura mental humana. Para Kant o espaço "é uma representação a priori necessária que subjaz a todas as intuições externas [...]. O espaço é intuição pura” (p. 41). E segue-se o mesmo padrão com referência ao tempo.
}

Sapere aude - Belo Horizonte, v. 7 - n. 12, p. 58-69, Jan./Jun. 2016 - ISSN: 2177-6342 
Em novembro de 1963, por ocasião de uma longa contemplação das Meninas no Prado, (Foucault) entrevira as grandes linhas de uma história da passagem da idade da representação `a idade da antropologia. Publicar sua tese secundária que a anunciava sem conhecer o método para fazê-lo tornava-se contraprodutivo. Era em uma configuração recente do saber - saber da produção, do ser vivo e das línguas -, e não no destino da filosofia moderna, que ele doravante situava a emergência e o provável desaparecimento da figura do homem surgida no século XVIII como duplo empírico-transcendental. (DEFERT, et.al., 2011, p. 10).

Numa espécie de espiral discursiva, o texto de As palavras e as coisas mostra que, se a relação entre palavras e coisas inicia-se, à guisa de proposta, pela diferenciação nítida entre esses dois campos, denominados palavras e coisas, ela se desenvolve, não obstante, a partir da indiferenciação entre seus significados mais profundos - apontada pelas franjas do passado recente ao século clássico; passa a seguir por uma nova diferenciação para, por fim, unirem-se num mesmo corpo, agora apontado pelas franjas do futuro. Mas esta última forma aparece invertida em comparação com a primeira indiferenciação, pois trata-se agora da forma do próprio modo da mente humana. E esta não é mais a mente imaginativa, reflexo da percepção de um mundo em direção do homem. Aqui aparece a mente conceitual: do homem em direção ao mundo. Trata-se então dessa mente organizadora por comparação, sustentada pelas précategorias do tempo e do espaço que, por estarem encobertas pela percepção, permitem que os conceitos apareçam abstratos, flutuantes, praticamente sem forma, mas sustentados pelas palavras de um sujeito, e que a partir desse momento, protagonizam uma esfera que vai além da representação ou da expressão. As palavras aparecem doravante como forjadoras de mundos de discursos, que também são coisas, ao mesmo tempo difusos - por se confundirem numa multiplicidade indefinida -, e científicos, por proporcionarem precisão e clareza dentro do recorte da especificidade de seus contextos.

Esse desenvolvimento será confirmado (talvez performatizado ou mesmo prescrito) pelas críticas e pela antropologia kantianas, que exporão o paradoxo da subjetividade como elemento da universalidade, ao mesmo tempo em que cada um desses termo, quais sejam, sujeito e objeto, continuam ocupando seus campos próprios. Na visão de Foucault esse paradoxo não só se realiza, como também faz sentido em seu próprio modo de cisão e complementaridade, o qual pode ser resumido numa dinamicidade (troca) intrínseca da forma de vida do homem pensante moderno. Nos termos kantianos esse paradoxo trata da impossibilidade de esgotar a problemática da relação do originário transcendental com o sentido de sujeito, e da relação desses conceitos com a irredutível questão da percepção 
fundamental. Foucault dirá sobre isso (2011, p. 94-5):

\begin{abstract}
Interrogando-se sobre as relações entre a dispersão temporal e a universalidade da linguagem, isto é, sobre o originário, uma Antropologia situa-se em uma problemática que é a de um mundo já dado. (...) A problemática da filosofia contemporânea (é) esta dispersão que nenhuma confusão, dialética ou fenomenológica, terá o direito de reduzir, e que reparte o campo de toda reflexão filosófica segundo o a priori, o originário e o fundamental. Desde Kant, implicitamente, o projeto de toda filosofia será o de superar essa essencial divisão, até que se torne clara a impossibilidade de semelhante ultrapassagem fora de uma reflexão que a repete e, repetindo-a, funda-a.
\end{abstract}

O símbolo da época clássica, a dobra histórica pontuada em As palavras e as coisas, é o quadro As meninas, analisado no primeiro capítulo do livro e ponto de partida da espiral discursiva. O quadro será interpretado por Foucault através da leitura de todos os traços levantados de sua estrutura, como se esses elementos fossem portadores de sentidos convergentes `a mensagem simbólica icônica do classicismo proposto pelo livro. E se nesse movimento de interpretação, Foucault procede a partir do desvendamento de camadas de sentidos, maneira aparentemente aproximada dos modos de interpretação medieval, em que uma coisa sempre remete a outra ao infinito, aqui o filósofo remete todos os sentidos, não a algo imaginado fora do discurso, mas sim ao seu próprio texto e contexto, ao seu discurso como corpus autônomo, performatizando assim essa nova indistinção entre palavra e coisa na sua contemporânea filosofia.

\title{
III
}

É já nesse primeiro capítulo que Foucault apresenta a problemática do sujeito como fonte ou fundamento, refletindo o paradoxo kantiano mencionado acima. Aquilo que, grosso modo, podemos perceber - até mesmo pela organização da língua - como centro irradiador dos sentidos de palavras e coisas, aqui simbolizado, como conteúdo do discurso, pelo sujeitopintor, se delineia num espelhamento ao infinito e, ao mesmo tempo, se perde como centro. $\mathrm{O}$ sujeito no limiar: "Como se o pintor não pudesse ser ao mesmo tempo visto $[\ldots]$ e ver $[\ldots]$. Ele reina no limiar dessas duas visibilidades incompatíveis" (FOUCAULT, 1967, p. 18).

O quadro, por sua vez, é lido como objeto estruturado nos significados colhidos dos dados fornecidos pela ordenação da sensorialidade (verticalidade, horizontalidade, etc.) segundo o conceito de espaço. Não se trata do sensorial puro, dos sentidos mesmo, mas sim 
do sensorial refletido e suposto através do conceito de espaço. Por meio desse conceito, Foucault vai nos ensinando a ver o quadro de Velásquez, evidenciando que a leitura é feita `a revelia da própria obra, e sua leitura é uma espécie de demonstração do que é possível ler ali.

Mas nesse movimento de análise, é como se Foucault adicionasse espelhos em um labirinto: sua palavra é sua interpretação e, por espelhamento, essa palavra é a própria representação de quem fala. Foucault é essa palavra que eu, agora, embora utilizando um nome próprio como referência do que leio, por minha vez espelho, uso a palavra Foucault como resumo do discurso espelhado no meu discurso. A espacialidade do quadro se sutiliza em deslocamentos, evidenciando essa natureza abstrata do conceito, típica do modo de pensar da nossa cultura contemporânea: um espaço sem lugar, porém pulverizado potencialmente em tudo quanto é lugar. E obtusamente, contudo, persiste a noção do "eu" como centro indefinido: "É que, neste quadro, como em toda representação de que ele é, por assim dizer, a essência expressa, a invisibilidade profunda do que se vê talvez seja solidária com a invisibilidade daquele que vê" (FOUCAULT, 1967, p. 32).

Então a palavra é que constrói a noção de sujeito. Na verdade não há separação entre essas duas coisas. O eu é construído, entrevisto e ocultado, é invisível e ao mesmo tempo visível pela palavra. Aqui não se trata da palavra "para" alguma coisa, apesar de parecer ser isso; trata-se da palavra mesmo como ser, como coisa. Trata-se de uma alternativa construtória da coisa como suporte do sujeito, quando, ao mesmo tempo, o sujeito não se define também no mesmo nível de clareza da coisa. Enquanto As meninas permanece clara coisa, única e delimitada, seu sujeito é múltiplo e difuso, porque essa coisa sendo espelho, o sujeito que se vê nele se multiplica pelo labirinto. O "mesmo" difuso e difundido, e o "outro" estabilizado e definido na precariedade do abstrato espaço. Espaço que é linha, cor, quadro e palavra.

Essa convergência da noção do "eu" como contígua à palavra novamente nos remete ao alinhamento de Foucault `a herança kantiana. Em Kant, se a objetividade é o resultado do funcionamento da intuição, equipada de seu aparato lógico-formal, e esta está sempre associada ao sentido interno, à intuição empírica, as formas do objeto serão sempre reduzidas à subjetividade, já que esta parece se constituir também como o produto da memória das experiências, como o faz entender a própria explicação de Kant logo no início do texto da sua Antropologia, quando fala sobre a formação da noção do "eu". Nesse ponto Kant parece nos mostrar que a noção da subjetividade aparece apenas depois de uma quantidade suficiente de 
experiências ter ocorrido na vida do sujeito que, então, poderá conduzi-las e ampliá-las sob a unidade indicada pela expressão linguística "eu":

\footnotetext{
Que o ser humano possa ter o eu em sua representação, eleva-o infinitamente acima de todos os demais seres que vivem na terra. É por isso que ele é uma pessoa, e uma e mesma pessoa em virtude da unidade da consciência em todas as modificações que lhe possam suceder [...] assim como todas as línguas têm de pensá-lo quando falam na primeira pessoa [...]. (KANT, 2006, p. 28).
}

Complementando essa questão, lembramos a interessante observação de Daniel Omar Perez sobre o ângulo do caráter puramente lingüístico da noção de "eu” na Antropologia de Kant: [...] A particularidade é que $e u$ é um tipo de representação da qual temos conhecimento pela linguagem. Não seríamos mais do que kantianos se afirmássemos a proposição conhecemos o eu porque temos linguagem (PEREZ, 2009, p. 386).

Em Foucault encontramos o complemento a esta abordagem:

Não é decerto possível dar valor transcendental aos conteúdos empíricos nem deslocá-los para o campo de uma subjetividade constituinte sem dar lugar, pelo menos tacitamente, a uma antropologia, quer dizer, a um modo de pensamento onde os limites do direito do conhecimento (e, por consequência, de todo o saber empírico) são ao mesmo tempo as formas concretas da existência tais quais se apresentam precisamente nesse mesmo saber empírico. (FOULCAULT, 1974, p. 326).

E para terminarmos de um modo um pouco poético, lembramos o escritor português Vergílio Ferreira, que interpreta a questão do sujeito em Foucault - em um artigo introdutório ‘a edição de As palavras e as coisas utilizada neste nosso trabalho - da seguinte forma: "Ser homem é assumirmo-nos em tudo o que é do homem. [...] O sujeito só morrerá quando se tornar possível conceber um existente, sem alguém que o conceba; e paralelamente se conceber um alguém que o conceba sem a consciência de que o conceba" (1967, p. 4).

\section{REFERÊNCIAS}

DFERT, Daniel, et. al. Apresentação da edição francesa. In: Gênese e estrutura da Antropologia de Kant. São Paulo: Loyola, 2011.

FOUCAULT, Michel. As palavras e as coisas. São Paulo: Martins Fontes por acordo com Portugália Editora Ltda, 1967.

FOUCAULT, Michel. Gênese e estrutura da antropologia de Kant. Trad. Márcio Alves da 
Fonseca; Salma Tannus. São Paulo: Loyola, 2011.

FERREIRA, Vergílio. Questionação a Foucault e a algum estruturalismo. In FOUCAULT, Michel. As palavras e as coisas. SP: Martins Fontes por acordo com Portugália Editora Ltda, 1967.

PRADO FILHO, Kleber. In: Michel Foucault e o discurso: aportes teóricos e metodológicos. In: MARQUES, Welisson; CONTI, Maria Aparecida; FERNANDES, Cleumar Alves (org.). Uberlândia: EDUFU, 2013.

KANT, Immanuel. Antropologia de um ponto de vista pragmático. Trad. Clélia Aparecida Martins. São Paulo: Iluminuras, 2006.

PEREZ, Daniel Omar. A antropologia pragmática como parte da razão prática em sentido kantiano. Campinas. Manuscrito, v. 32, n. 2, p. 357-397, jul.-dez. 2009. 